\title{
Padrões Evolutivos na Utilização dos Princípios de Justiça Distributiva em Crianças e Adolescentes no Sul do Brasil
}

\author{
Débora Dalbosco Dell'Aglio ${ }^{123}$ \\ Universidade Federal do Rio Grande do Sul e Universidade do Vale do Rio dos Sinos \\ Claudio Simon Hutr. \\ Universidade Federal do Rio Grande do Sul
}

\begin{abstract}
Resumo
O presente artigo descreve uma investigação sobre o uso de princípios de justiça distributiva utilizados por crianças e adolescentes em situações hipotéticas de distribuição de recompensa. Foram entrevistadas 680 crianças e adolescentes de ambos os sexos, sendo 240 da faixa etária de cinco a seis anos, 220 de nove a dez anos e 220 de 13 a 14 anos, metade de cada sexo. O instrumento utilizado foram mini-histórias, acompanhadas de desenhos que apresentavam diferentes condições de desempenho dos personagens em diversas situações. Os resultados apontaram três estágios evolutivos, caracterizados pelo uso de regras de autoridade, igualdade e equidade. Como esperado, crianças de cinco a seis anos utilizaram predominantemente regras de autoridade e igualdade, as de nove a dez anos, regras de igualdade e, os adolescentes, regras de eqüidade. Características do uso das regras permitiram também a identificação de sub-estágios em cada estágio. A seqüência evolutiva de níveis no desenvolvimento dos princípios de justiça distributiva encontradas apoiam o modelo piagetiano.

Palavras-chave: Justiça distributiva; eqüidade; igualdade.
\end{abstract}

Developmental Patterns in the Use of Distributive Justice Principles by Southern Brazilian Children and Adolescents

\begin{abstract}
The present study investigated developmental patterns of use of distributive justice principles by children and adolescents in hypothetical situations that required distribution of rewards. The participants were 680 children and adolescents of both genders, 240 of whom were 5-6 years old, 220 9-10 years old, and 220 13-14 years old. The interview used four short stories and drawings which depicted different situations of performance. The results showed three stages characterized by the use of rules of authority, equality, and equity. As expected, young children employed rules of authority and equality, 9-10 year olds used mostly rules of equality, whereas the adolescents preferred equity. The differential usage of rules allowed for the identification of sub-stages within each stage. The sequence of developmental levels of distributive justice principles is coherent with Piaget's model.

Keywords: Distributive justice; equality; equity.
\end{abstract}

O estudo psicológico do conceito de justiça remonta a década de 1930 (Piaget, 1932/1977) e tem produzido uma literatura extensa e, por vezes, controversa (Adams, 1965; Deutsch, 1975, 1986; Furby, 1986; Lerner, 1974; Leventhal, 1970, 1973; entre outros). No Brasil, as primeiras investigações envolvendo justiça distributiva foram realizadas por pesquisadores ligados ao ISOP/ FGV, a partir de 1985 (Assmar, 1985; Assmar e cols., 1987; Rodrigues, 1985; Rodrigues \& Assmar, 1988).

\footnotetext{
${ }^{1}$ Endereço para correspondência: Instituto de Psicologia, UFRGS, Ramiro Barcelos 2600, Porto Alegre, RS, 90035-003.E-mail: hutzc@ufrgs.br

${ }^{2}$ Este trabalho foi parcialmente financiado pelo CNPq e Fapergs.

${ }^{3}$ Agradecemos a Analúcia Schliemann e Cílio Ziviani por contribuições relevantes para o delineamento dos estudos e a Renata Prosdocimi que colaborou na transcrição e categorização dos dados.
}

Vários princípios distributivos têm sido propostos para explicar as formas de alocação de recursos utilizadas por pessoas ou grupos. Adams (1965) propôs um princípio de eqüidade, cujo ponto central consiste na aplicação da regra Aristotélica de que o justo é a distribuição proporcional. A eqüidade, portanto, é baseada no princípio de que a divisão de recursos é feita de acordo com investimentos definidos, como habilidade, inteligência, esforço, etc. (Sampson, 1975).

Dois outros princípios que também têm sido usados como critérios de justiça distributiva são a igualdade e a necessidade (Deutsch, 1975). O primeiro determina que a divisão de recursos seja feita de tal forma que os participantes recebam a mesma quantidade de recursos independentemente de condições de esforço, capacidade ou necessidade. O segundo, determina que a alocação 
de recursos seja baseada no grau de necessidade dos agentes envolvidos; isto é, cada indivíduo recebe de acordo com suas necessidades e não com base em suas contribuições.

Diversos fatores influenciam na escolha do princípio a ser usado na distribuição de recursos. Entre eles, destacam-se fatores referentes às características situacionais (complexidade da tarefa, incentivos, papel do alocador como participante ou terceira parte, objetivos propostos, informações fornecidas, etc.), fatores relativos à pessoa (atributos genéticos ou de aprendizagem tais como idade, sexo, raça, desenvolvimento cognitivo, entre outros), ou ainda, referentes à cultura e à ideologia predominante na sociedade, além de outras situações específicas, tais como competitividade ou de cooperação, valor dos recursos a serem distribuídos, presença ou ausência de autoridade (Cook \& Hegtvedt, 1983; Hook, 1983; Hook \& Cook, 1979; Vikan, 1986).

A literatura sobre o comportamento de alocação da criança é ainda muito escassa. No entanto, pesquisas recentes sobre comportamento pró-social sugerem que a criança desenvolve a compreensão social muito cedo em sua vida e que este desenvolvimento afeta suas idéias de justiça (Wender, 1986).

Piaget (1932/1977), que foi um dos primeiros a estudar justiça distributiva em crianças, apresentou um modelo de desenvolvimento de justiça distributiva em três grandes estágios. No primeiro, que se estende até sete ou oito anos, a criança atribui a justiça à autoridade dos adultos ou das crianças mais velhas, havendo uma indiferenciação das noções de justo e de injusto com as noções de dever e de obediência: o justo é o que está de acordo com as ordens impostas pela autoridade adulta. No segundo estágio, entre oito e 11 anos, há um desenvolvimento progressivo da autonomia e a primazia da igualdade sobre a autoridade. O igualitarismo desenvolve-se e prevalece sobre outras considerações. No conflito entre autoridade e igualdade, como regra, a igualdade terá primazia. Por volta dos 11 a 12 anos, ao alcançar o terceiro estágio, o igualitarismo simples cede lugar à eqüidade, que consiste em não definir a igualdade sem considerar a situação particular de cada um, fazendo com que a decisão se torne mais efetiva (justa).

Damon (1975) demonstrou que o desenvolvimento da justiça positiva na criança pode ser descrito numa seqüência de níveis relacionados à idade, apresentados num modelo com seis estágios de justiça distributiva. No Nível O-A, até quatro anos, a justiça deriva do que a criança quer que ocorra, e ela acredita que se quer ganhar mais ela deve ganhar mais. No Nível O-B, de quatro a cinco anos, a justiça reflete o desejo do próprio sujeito mas justificada por características externas como tamanho, sexo, ou outras características físicas das pessoas. Já no Nível l-A (cinco a sete anos), a justiça deriva de noções de igualdade e todos devem receber o mesmo, de forma unilateral e inflexível. A justiça só deriva da noção de reciprocidade nas ações no Nível l-B (seis a nove anos), quando a criança acredita que aqueles que trabalharam mais ou melhor que outros devem receber mais. No Nível 2-A (oito a dez anos), a relatividade moral surge do entendimento de que diferentes pessoas podem ter diferentes justificativas para seus direitos serem justos. Finalmente, no Nível 2-B, após os dez anos, não há mais preferência por nenhum princípio pois a criança é capaz de reconhecê-los e coordená-los sistematicamente.

Kohlberg (1984) apresenta um modelo de seis estágios onde a justiça distributiva é feita baseada em operações como igualdade, mérito e eqüidade. No primeiro estágio, de moralidade heterônoma, a justiça é guiada por igualdade estrita mas com obediência ou respeito à autoridade. No segundo estágio, surge a coordenação entre igualdade e reciprocidade enquanto que no terceiro estágio a criança já considera as normas sociais como base para a distribuição e coordena então operações de igualdade, reciprocidade e eqüidade. No quarto estágio, a criança baseia a distribuição na coordenação das três operações de justiça do estágio anterior mas com imparcialidade, respeito às instituições sociais, consideração ao mérito social e contribuição à sociedade. No quinto estágio as operações de justiça são estruturadas em torno do respeito aos direitos humanos e de uma hierarquia racional de direitos e valores em relação a processos de cooperação e concordância social. No último estágio, o princípio da eqüidade é usado, mas reconhecendo diferenças de necessidade.

Hook (1982) sugere que o desenvolvimento do julgamento de justiça da criança tem estreita relação com a habilidade matemática e com os conceitos de proporcionalidade, afirmando que somente adolescentes e adultos podem realmente usar a eqüidade. Para ele, crianças de diferentes idades fazem tipos de alocações de recursos qualitativamente diferentes porque elas têm capacidades diferentes para lidar com os conceitos lógicomatemáticos de proporcionalidade. Dessa forma, Hook faz uma distinção ao definir eqüidade, apresentando três diferentes etapas no seu desenvolvimento: eqüidade nominal (até os sete anos), eqüidade ordinal (dos sete aos 13) e eqüidade proporcional, na adolescência. Esta seqüência é consistente com a seqüência normal do desenvolvimento lógico-matemático, sugerindo que o comportamento de alocação observado pode ser uma função da habilidade cognitiva. 
Diversas pesquisas têm enfocado o comportamento da criança em relação à justa alocação de recursos. Os resultados têm, em geral, identificado uma direção relacionada à idade na escolha do princípio de distribuição. As crianças passam de um período em que prevalecem as alocações baseadas no auto-interesse para um período de igualdade, surgindo depois a ênfase no princípio de eqüidade (Hook \& Cook, 1979; Wender, 1986). Sales (2000) também demonstra uma evolução, na utilização dos princípios de justiça distributiva, passando da igualdade para o princípio de eqüidade, que é acompanhada do desenvolvimento da autonomia. No entanto, os resultados e os princípios utilizados variam, de acordo com as situações utilizadas nos diferentes estudos.

Vikan (1986) investigou a alocação de recursos em tarefas que apresentavam diferenças na produção, no esforço e na contribuição relativa de cada sujeito. Seus resultados mostram que a maioria das crianças, em diferentes faixas etárias, usou a igualdade quando havia diferenças de esforço e a eqüidade quando a diferença era somente na produção. Peterson e cols. (1975) apresentaram histórias sobre diferenças no desempenho para crianças pré-escolares e os resultados mostraram uma preferência pela igualdade na alocação das recompensas. Esta preferência se manteve tanto na situação em que a diferença no desempenho era qualitativa como quando era quantitativa, moderada ou grande ou expressa em comprimento ou área. Em estudos brasileiros (Hutz, Vargas \& Conti, 1989, 1991, 1994) com estudantes universitários, houve predominância do uso da regra de igualdade em praticamente todas as situações, embora o uso da regra da equidade ocorresse quando sua utilização não gerasse uma distribuição desigual.

Diferenças de gênero na alocação de recursos tem sido encontradas, mas de forma inconsistente. Algumas pesquisas indicaram que meninos apresentam uma maior preferência por eqüidade do que meninas (Benton, 1971; Leventhal \& Anderson, 1970), enquanto outras não encontram diferenças de sexo no comportamento de alocação (Hutz, Vargas, \& Conti, 1994; Lane \& Coon, 1972; Lerner, 1974).

Quanto à percepção da injustiça em situações de distribuição de recompensa, Wender (1986) cita alguns estudos em que crianças julgaram como justa uma distribuição igualitária e como injusta uma distribuição que levava em consideração o esforço dos personagens e que era, portanto, eqüitativa. Este tipo de achado, embora importante, indica apenas que crianças que utilizam um princípio de igualdade para fazer alocações vêem como injustas distribuições que resultam da utilização de outro princípio que elas ainda não são capazes de entender.

O presente artigo apresenta os resultados obtidos com crianças e adolescentes de diferentes faixas etárias, manipulando as variáveis quantidade e qualidade do trabalho. Para isso, procurou-se uma situação na qual a criança pudesse dividir os recursos entre outras crianças, hipoteticamente, através de mini-histórias em que aparecessem diferentes condições para a distribuição de uma recompensa. Além disso, manipulou-se também a situação, solicitando aos participantes que julgassem a justiça de uma distribuição (igualitária, eqüitativa ou injusta) feita por uma professora. Nossa hipótese era de que a utilização desse conjunto de procedimentos permitiria identificar com mais clareza o uso das regras distributivas. Quando solicita-se a crianças que façam uma distribuição (como nos estudos de Damon), não é obviamente possível identificar a submissão a regras de autoridade. Quando a criança apenas julga, autoridade e igualdade são confundidas. O emprego simultâneo de julgamento e ação deve permitir a identificação de um modelo mais completo de desenvolvimento do conceito de justiça distributiva.

\section{Participantes}

\section{Método}

Participaram da pesquisa 680 crianças, metade de cada sexo, divididas em três faixas etárias: 240 crianças de cinco a sete anos incompletos $(M=6,2 ; d p=0,50), 220$ crianças de nove a 11 anos incompletos $(M=9,7 ; d p=0,51)$ e 220 adolescentes de 13 a 15 anos incompletos $(M=14,0$; $d p=0,57)$. Todos eram alunos de escolas públicas da rede estadual e municipal da cidade de Porto Alegre, e o nível sócio-econômico da amostra era médio-baixo a baixo. As crianças de cinco a seis anos freqüentavam a préescola; as de nove e dez anos freqüentavam a terceira série; as de 13 e 14 anos a sétima ou oitava série do Primeiro Grau.

\section{Instrumento}

Foram construídas quatro mini-histórias, tomando como base a Distributive Justice Scale (Enright, Franklin \& Manheim, 1980; Enright, Manheim \& Harris, 1980). Cada uma das mini-histórias representa uma situação diferente que envolve sempre dois personagens, meninos de uma mesma turma, que pintam alguns quadrinhos a pedido da professora. Na primeira história, um dos personagens pinta quatro quadrinhos, enquanto que o outro pinta dois, apresentando uma situação de diferença na quantidade de trabalho realizado (maior número de quadrinhos pintados). Na segunda história, um dos personagens pinta 
dois quadros com capricho e o outro pinta a mesma quantidade de quadros mas sem vontade, apresentando uma situação de diferença de qualidade na execução do trabalho (pinturas mais bonitas). $\mathrm{Na}$ terceira história, não há diferença nem na quantidade nem na qualidade da produção. A quarta história é similar à segunda. Um dos personagens pinta três quadros com capricho e o outro pinta a mesma quantidade de quadros mas sem vontade, apresentando também uma situação de diferença de qualidade na execução do trabalho. Esta condição, por apresentar o mesmo número de quadros usados nas histórias um e três permite controlar o efeito da desproporcionalidade introduzida na história dois. Cada história é acompanhada de um desenho de acordo com a situação apresentada (Anexo A).

\section{Procedimento}

O instrumento foi aplicado individualmente a cada participante. Era contada a mini-história selecionada, apresentando ao mesmo tempo a figura de acordo com a condição envolvida. A história, condição e situação a ser aplicada era escolhida aleatoriamente para cada criança, até o limite de dez crianças. Após contar a história era solicitado à criança que distribuísse a recompensa (seis balas) entre os dois personagens, colocando as balas sobre as figuras. Nas situações em que a professora fazia a distribuição da recompensa, as balas eram colocadas sobre as figuras pelo entrevistador, de acordo com a distribuição selecionada.

$\mathrm{Na}$ situação em que a criança fazia a distribuição, era investigada a razão de sua distribuição, perguntando depois porque a fez daquela maneira. $\mathrm{Na}$ segunda situação, as histórias foram apresentadas com uma distribuição realizada pela professora, que poderia seguir o princípio da igualdade (distribuição 3/3), o princípio da eqüidade (distribuição 4/2) ou ainda um princípio injusto (distribuição $2 / 4$, premiando quem produzia menos ou pior), solicitando que a criança julgasse o fim apresentado. Quando a criança considerava o fim como "não certo" ou injusto era perguntada sobre como ela faria a divisão e por quê.

Na situação "injusta" a história era finalizada de tal forma que a professora dava uma maior recompensa para o personagem que pintou menos quadros (condição de diferença na quantidade de trabalho), ou para o que pintou quadros mais feios (condição de diferença na qualidade do trabalho), ou para um dos dois (condição de igualdade).

Todas as entrevistas foram gravadas e transcritas. Para o levantamento dos resultados foram estabelecidas categorias para classificação do princípio de justiça distributiva apresentado na primeira resposta e para suas justificativas.

As categorias de princípios, definidas a priori, foram as seguintes:

Autoridade: quando a criança concordava com a distribuição apresentada, sem no entanto explicar porque tal distribuição estava certa ou ainda tentando justificar porque a professora distribuiu a recompensa daquela forma.

Igualdade: quando a criança considerava que os dois personagens deviam receber a mesma recompensa, desconsiderando diferenças existentes na quantidade ou na qualidade do trabalho, enfatizando a igualdade em algum aspecto.

Eqüidade: quando a criança considerava a diferença na quantidade (maior número de quadros) ou na qualidade (quadros mais bonitos), para distribuir a recompensa, resultando em diferentes quantidades para cada personagem.

Outro: quando a criança apresentava uma resposta cuja distribuição não fazia sentido ou ainda que não se enquadrasse em nenhum dos princípios citados acima.

\section{Resultados}

As respostas das crianças foram classificadas em um dos princípios e foram realizadas análises observando as freqüências de utilização de cada princípio, conforme as diferentes situações de finalização das histórias, considerando as variáveis faixa etária, sexo e condições experimentais (diferença na quantidade, diferença na qualidade e igualdade de produção).

Uso de Princípios de Justiça Distributiva na Situação em que a Criança faz a Distribuição: Nesta situação os resultados indicaram um predomínio na utilização do princípio de igualdade nas faixas etárias de cinco-seis $(80,7 \%$ das respostas desta faixa) e de nove-dez anos (75\%), e o predomínio do princípio de eqüidade na faixa de 13-14 anos $(58,3 \%)$ Foram encontradas diferenças significativas entre a faixa de 5-6 anos e 13-14 $\left(X^{2}=6,21 ; g l=1 ; p<\right.$ $0,05)$ e entre a faixa de $9-10$ e $13-14\left(X^{2}=5,71 ; g l=1 ; p\right.$ $<0,05)$. Entre as faixas de 5-6 e 9-10 não foram encontradas diferenças significativas. Também não foram significativas as diferenças entre os sexos e entre as condições.

Uso de Princípios de Justiça Distributiva nas Situações de Distribuição Igualitária on Eqüitativa: A freqüência da utilização de cada princípio, nas situações de distribuição igualitária e eqüitativa, é apresentada na Tabela 1, por faixa etária. O princípio de autoridade foi utilizado quase que exclusivamente pelas crianças de cinco-seis anos (95,3\% 
Tabela 1. Freqüência de Utilização dos Princípios Distributivos por Faixa Etária nas Situações de Distribuição Igualitária e Eqüitativa

\begin{tabular}{lrrrr}
\hline Princípios & Faixas & Etárias & $13-14$ & Total \\
& $5-6$ & $9-10$ & & \\
\hline Autoridade & 41 & 2 & - & 43 \\
Igualdade & 34 & 57 & 39 & 130 \\
Eqüidade & 24 & 39 & 61 & 124 \\
Total & 99 & 98 & 100 & \\
\hline
\end{tabular}

das respostas de autoridade). O princípio de igualdade predominou na faixa etária de 9-10 anos $(43,8 \%)$ e o de eqüidade na faixa de 13-14 anos (49,2\%).

Uma análise por faixa etária mostrou que na faixa de 5-6 anos houve diferença significativa entre o uso da autoridade e da eqüidade $\left(X^{2}=4,44 ; g l=1 ; p<0,04\right)$. $\mathrm{Na}$ faixa de 9-10 anos, predominou o uso da igualdade com $58,1 \%$ do total de respostas e houve diferença significativa entre os princípios $\left(X^{2}=48,14 ; g l=2 ; p<\right.$ $0,01)$. Na faixa de 13-14 anos, a diferença no uso dos princípios distributivos também foi significativa $\left(X^{2}=\right.$ 57,26; $g l=2 ; p<0,01)$, com predomínio do uso da regra de eqüidade com $61 \%$ do total de respostas.

$\mathrm{Na}$ análise por condições houve maior freqüência do princípio de eqüidade, na condição de diferença na qualidade $(61,5 \%)$ com diferenças significativas entre os princípios $\left(X^{2}=42,92 ; g l=2 ; p<0,01\right)$. Na condição de diferença na quantidade (condição 1 ) e na condição de igualdade (condição 3) predominou o princípio de igualdade com $51,6 \%$ e $68,3 \%$ das respostas, respectivamente. Houve diferença significativa entre as respostas na condição de diferença na quantidade $\left(X^{2}=\right.$ $23,15 ; g l=2 ; p<0,01)$ e diferença significativa entre as respostas na condição de igualdade $\left(X^{2}=34,3 ; g l=2 ; p\right.$ $<0,01)$.

$\mathrm{Na}$ Tabela 2 podemos observar os efeitos das situações de Distribuição Igualitária e Eqüitativa, por faixa etária.
$\mathrm{Na}$ faixa etária de 5-6 anos, houve um incremento na utilização do princípio de igualdade $(45,8 \%)$ na situação de distribuição igualitária e do princípio de eqüidade $(45 \%)$ na situação de distribuição eqüitativa. Além disso, foi grande o uso do princípio de autoridade, representando $44 \%$ das respostas na situação de distribuição igualitária e 37,5\% das respostas na situação de distribuição eqüitativa, indicando que $41,4 \%$ das respostas seguiram o princípio de autoridade nesta faixa. A diferença entre as proporções do princípio de igualdade $(45,8 \%$ e $17,5 \%)$ e do princípio de eqüidade $(10,2 \%$ e $45 \%)$ foram significativas $(Z=3,97 ; p<0,05$ para igualdade e $Z=3,97 ; p<0,05$ para eqüidade).

Observou-se que na faixa etária de 9-10 anos o princípio de igualdade foi predominante nas duas situações, e na faixa etária de 13-14 anos o uso do princípio de eqüidade foi superior também nas duas situações apresentadas, não havendo diferenças significativas para nenhum princípio nas duas faixas etárias.

Uso dos Princípios de Justiça Distributiva na Situação de Distribuição Injusta: Nesta situação, 39\% das crianças de 56 anos não reconheceram a injustiça e concordaram com a distribuição apresentada. Entre as crianças de 9-10 anos predominou o uso da igualdade $(51,7 \%)$ e na faixa de 13-14 predominou a eqüidade com $53,3 \%$ das respostas.

Foram encontradas diferenças significativas de gênero nesta situação, apontando para um maior uso da igualdade pelas meninas $(50 \%)$ do que pelos meninos $(33,7 \%)$ $(Z=2,23 ; p<0,05)$ e um maior uso da eqüidade pelos meninos (51,6\%) do que pelas meninas $(37,7 \%)(Z=1,9$; $p<0,05) . \mathrm{Na}$ análise por condições observou-se diferenças significativas entre os princípios, sendo que tanto na condição de diferença na quantidade, como na de diferença na qualidade, predominou o princípio da eqüidade (53,3\% e 55,9\% das respostas respectivamente). $\mathrm{Na}$ condição de igualdade na produção predominou a utilização do princípio de igualdade (55\%).

Diferenças na Utilização de Princípios de Justiça Distributiva entre as Situações Experimentais: $\mathrm{Na}$ Tabela 3 podemos observar a freqüência de utilização de cada princípio, nas

Tabela 2. Percentuais de Utilização dos Princípios Distributivos por Faixa Etária nas Situações de Distribuição Igualitária e Eqüitativa

\begin{tabular}{|c|c|c|c|c|c|c|}
\hline \multirow{4}{*}{ Princípio } & \multicolumn{6}{|c|}{ Faixa Etária } \\
\hline & \multicolumn{2}{|c|}{ 5-6 anos } & \multicolumn{2}{|c|}{ 9-10 anos } & \multicolumn{2}{|c|}{ 13-14 anos } \\
\hline & \multicolumn{2}{|c|}{ Distribuição } & \multicolumn{2}{|c|}{ Distribuição } & \multicolumn{2}{|c|}{ Distribuição } \\
\hline & Igual. & Equitat. & Igual. & Equitat. & Igual. & Equitat. \\
\hline Autoridade & 44,0 & 37,5 & 1,7 & 2,5 & - & - \\
\hline Igualdade & 45,8 & 17,5 & 56,9 & 60,0 & 36,7 & 42,5 \\
\hline Equidade & 10,2 & 45,0 & 41,4 & 37,5 & 63,3 & 57,5 \\
\hline
\end{tabular}


Tabela 3. Freqüência de Utilização dos Princípios Distributivos nas Diferentes Situações

\begin{tabular}{|c|c|c|c|c|c|}
\hline \multirow[b]{3}{*}{ Princípio } & \multicolumn{4}{|c|}{ Situações } & \multirow{3}{*}{ Total } \\
\hline & \multirow{2}{*}{$\begin{array}{c}\text { Criança Faz } \\
\text { a Distribuição }\end{array}$} & \multicolumn{3}{|c|}{ Criança Julga uma Distribuição } & \\
\hline & & Distrib.Igual. & Distrib.Equit. & Distrib.Injusta & \\
\hline Autoridade & - & 27 & 16 & 24 & 67 \\
\hline Igualdade & 116 & 82 & 48 & 75 & 321 \\
\hline Eqüidade & 61 & 68 & 56 & 80 & 265 \\
\hline Total & 177 & 177 & 120 & 179 & 653 \\
\hline
\end{tabular}

situações em que a criança fez a distribuição da recompensa, e nas situações em que a criança julgou uma distribuição (situações de distribuição igualitária, eqüitativa ou injusta).

O princípio de autoridade, que obviamente só pode ser identificado nas situações em que a criança julga uma distribuição apresentada, não foi utilizado diferencialmente entre as demais situações $\left(X^{2}=2,89 ; g l=2 ; p<0,24\right)$. O uso do princípio de igualdade, que predominou na situação em que a criança realizava a distribuição, com $36,1 \%$ das respostas igualitárias, apresentou diferenças significativas entre as situações experimentais $\left(X^{2}=29,26\right.$; $g l=3 ; p<0,01)$. A maior freqüência de utilização do princípio de eqüidade ocorreu na situação de distribuição injusta, com $30,2 \%$ das respostas eqüitativas, mas não houve diferença significativa entre as situações.

Observando-se os resultados por faixa etária, foram encontradas diferenças significativas entre as situações, no uso do princípio de igualdade, na faixa etária de 5-6 anos $\left(X^{2}=34,25 ; g l=3 ; p<0,001\right)$, com uma maior freqüência nas situações em que a criança fazia a distribuição e na situação de distribuição igualitária ( $47,4 \%$ e $27,8 \%$ respectivamente). Também houve diferença significativa $\left(X^{2}=8,37 ; g l=3 ; p<0,05\right)$ na utilização do princípio de eqüidade, na faixa de cinco-seis anos, predominando nas situações de distribuição eqüitativa e injusta (33,3\% e 35,2\% das respostas respectivamente). Nas demais faixas etárias não foram encontradas diferenças significativas entre as situações.

Distribuição da Recompensa nas Condições de Diferença na Quantidade e na Qualidade do Trabalho: Inicialmente foi computado um índice resultante da diferença entre o número de balas distribuídas para cada personagem, sendo que, quando a distribuição era igualitária, o escore do sujeito era zero. Nas distribuições eqüitativas, o escore do sujeito podia variar de 1 a 6 e, quando a distribuição era injusta, o sujeito recebia um escore negativo (-2). Utilizando este índice, foi realizada uma análise de variância $2 \times 3 \times 2 \times 4$, tendo como variáveis independentes sexo, faixa etária, condição (maior quantidade ou melhor qualidade do trabalho) e situação (distribuição feita pelo sujeito, distribuição igualitária, eqüitativa ou injusta). Eliminou-se desta análise a condição de igualdade do trabalho, pois a distribuição era quase sempre igual para os personagens.

A primeira análise mostrou que as diferenças de sexo e de situação não foram significativas $[F(1,431)<1$ e $F(3,431)=2,6 ; p>0,09$, respectivamente]. A diferença entre as faixas etárias (médias de 0,72; 1,06 e 1,33 para as faixas de 5-6, 9-10 e 13-14 anos respectivamente) foi significativa $[F(2,431)=10,79 ; p<0,01]$. Observa-se um aumento progressivo das médias, indicando uma utilização crescente da regra de eqüidade a cada faixa. Um teste para exame de diferenças a posteriori (Scheffé) mostrou que a diferença entre a faixa de cinco-seis anos e a faixa de 13-14 anos é significativa $(p<0,05)$.

A eqüidade, na condição $2(M=1,28)$, foi significativamente maior do que na condição $1(M=0,79)$ $[F(1,431)=21,19 ; p<0,01]$, e as interações entre faixa etária e condições e entre faixa etária e situação foram significativas $[F(2,431)=6,1 ; p<0,01$ e $F(6,431)=6,64$; $p<0,01$, respectivamente]. Nenhuma das demais interações foi significativa.

$\mathrm{Na}$ análise por faixa etária, observou-se diferença significativa $[F(3,152)=12,0 ; p<0,01]$, na faixa etária dos cinco-seis anos, entre as situações (médias 0,$45 ; 0,28$; 1,65 e 0,50 para as situações de 1 a 4 respectivamente). Nas faixas etárias de 9-10 e 13-14 anos foi encontrada diferença significativa entre as condições 1 e $2([F(1,151)$ $=16,56 ; p<0,01]$ para 9-10 e $[F(1,152)=16,35 ; p<$ $0,01]$ para 13-14 anos) indicando um aumento no uso da eqüidade na condição 2 , de diferença na qualidade.

Análise das Justificativas: Identificação de Sub-estágios: Após a classificação das respostas nas categorias de autoridade, igualdade e eqüidade, uma nova análise das justificativas, permitiu a identificação de um conjunto de sub-categorias que aparentemente apresentam características evolutivas, e que podem se constituir em oito sub-estágios distintos. 
Os dois primeiros sub-estágios seguem o princípio de autoridade:

Sub-estágio 1A: a criança concorda com a distribuição apresentada, mas sem justificar.

Sub-estágio 1B: a criança concorda com a distribuição apresentada, justificando a atitude da professora. Ex: "é a professora quem manda", "a professora que sabe", "ela é boazinha", "ela gosta dos alunos".

Os quatro estágios seguintes envolvem o uso da regra de igualdade:

Sub-estágio 2: a criança faz uma distribuição igualitária, mas sem apresentar justificativa. Ex: "tem que ser igual".

Sub-estágio 3: a criança enfatiza o aspecto numérico da distribuição, falando em quantidades e em repartir. Ex: "seis dividido por dois é igual a três", "três mais três é igual a seis", "tem que ter a mesma quantidade".

Sub-estágio 4: a criança apresenta argumentos afiliativos para justificar sua resposta, referindo-se a sentimentos, embora reconheça a existência de diferença na produção entre os dois personagens. Ex: "para eles não brigarem", "para que um deles não fique com ciúmes", "para que nenhum fique chateado".

Sub-estágio 5: quando é apresentada uma justificativa que, mesmo em situações de diferença na qualidade ou na quantidade dos trabalhos, enfatiza a igualdade em algum aspecto, desprezando as diferenças existentes. Ex: "os dois fizeram", "os dois trabalharam", "os dois são colegas", "são seres humanos", "os dois obedeceram a professora".

Os últimos dois estágios se baseiam na regra da eqüidade:

Sub-estágio 6: a criança enfatiza a diferença na quantidade ou na qualidade dos trabalhos dos personagens. Ex: "esse fez mais", "esse fez mais bonito", "esse caprichou", "esse se esforçou mais", "esse fez 4 e esse fez 2".

Sub-estágio 7: é enfatizada a diferença na qualidade ou na quantidade do trabalho dos personagens, dando uma resposta mais complexa, indicando que a utilização da regra da eqüidade tem também valor formativo ou educacional. Ex: "ele aproveitou melhor o tempo", "ganhando menos ele pode ser estimulado a trabalhar mais da próxima vez", "pode ser que assim ele aprenda a se esforçar mais", "dessa forma ele pode ser estimulado a melhorar".

Observou-se uma correlação $r=0,47(p<0,001)$ entre os sub-estágios e a idade em anos. $\mathrm{Na}$ Figura 1 apresentamos as freqüências de cada princípio, por faixa etária. Dessa forma pode-se visualizar um padrão de desenvolvimento dos princípios em cada faixa etária. Como pode ser visto, os sujeitos na faixa etária de 5-6 anos apresentam uma tendência à redução da freqüência de respostas no sentido autoridade-igualdade-eqüidade. $\mathrm{Na}$ faixa etária dos 9-10 anos, há um pico na freqüência de igualdade. Na faixa etária dos 13-14 anos, a tendência é de aumento na freqüência de respostas, em direção à eqüidade.

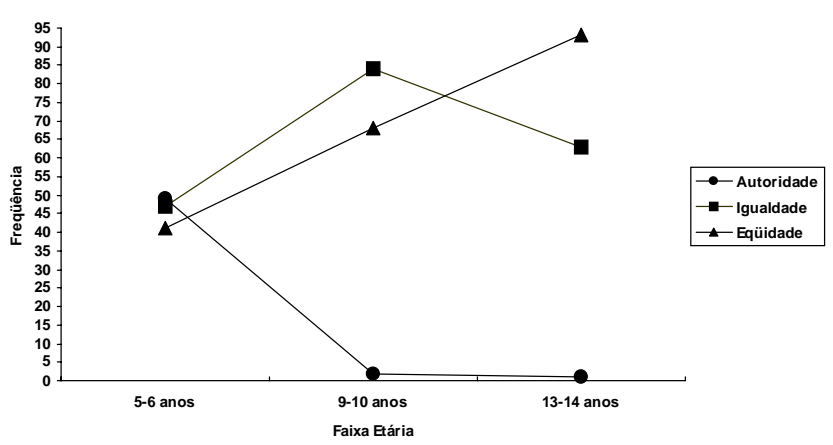

Figura 1. Freqüência de utilização dos princípios distributivos por faixa etária na situação que a criança julga a distribuição

$\mathrm{Na}$ análise das situações pode-se observar que nas situações de distribuição igualitária e eqüitativa houve uma maior freqüência das respostas de autoridade do tipo 1A (88,5\% das respostas de autoridade), enquanto que na situação de distribuição injusta a freqüência foi maior no sub-estágio 1B (76,4\% das respostas de autoridade).

$\mathrm{Na}$ análise das respostas da situação em que a criança distribuía a recompensa (não era possível identificar respostas de autoridade) observou-se uma freqüência de casos no sub-estágio 2, na faixa etária de 5-6 anos, muito superior à apresentada nas situações em que o uso da regra de autoridade podia ser reconhecido. Nas situações em que a professora fazia a distribuição, estas crianças apresentaram 3,1\% de justificativas no sub-estágio 2, enquanto que na situação em que a própria criança fazia a distribuição a freqüência foi de $33,3 \%$.

\section{Discussão}

Os resultados indicaram diferenças na utilização dos princípios de justiça distributiva por faixa etária em todas as situações. Na situação em que o sujeito faz a distribuição da recompensa, os dados indicaram a predominância da utilização do princípio de igualdade nas faixas etárias de cinco a seis anos e de nove a dez anos, e predominância do princípio de eqüidade na faixa etária de 13-14 anos. No entanto, o tipo de resposta igualitária (justificativa) das crianças de cinco a seis anos difere das de nove a dez anos. Nas situações em que a criança julga uma 
distribuição, os dados indicaram a predominância no uso do princípio de autoridade na faixa etária de 5-6 anos, do princípio de igualdade na faixa de 9-10 anos e do princípio de eqüidade na faixa de 13-14 anos. As diferenças apresentadas entre as faixas etárias indicaram um padrão evolutivo na utilização dos princípios distributivos utilizados. Os dados indicaram que as crianças menores utilizaram principalmente a autoridade e a igualdade, as de nove a dez anos preferiram a igualdade e os adolescentes, a eqüidade. Estes resultados estão de acordo com os achados de Piaget (1932/1977), que também apresenta três períodos diferentes no desenvolvimento da justiça distributiva.

Os níveis descritos por Damon (1975) diferem qualitativamente deste estudo pois apresentam princípios que não foram identificados na nossa amostra e não há referência ao princípio da autoridade em seu modelo. Como a autoridade foi aqui identificada como um princípio preponderante na faixa de cinco a seis anos, é possível que Damon não o tenha identificado pelas limitações metodológicas de seu estudo.

Neste estudo os resultados indicaram que em algumas situações (criança faz a distribuição e na situação em que é apresentada uma distribuição injusta) há um predomínio no uso da regra de eqüidade na condição de diferença na qualidade de trabalho (crianças acima de nove anos), contrariando estudos realizados com crianças e adultos. Vikan (1986), Peterson e cols. (1975), Hutz, Vargas e Conti (1989, 1991, 1994) indicaram, em seus estudos, preferência pela igualdade em qualquer condição.

Não foram encontradas diferenças significativas de gênero, exceto na situação de distribuição injusta, em que as meninas utilizaram o princípio de igualdade com mais freqüência e os meninos utilizaram o princípio de eqüidade com mais freqüência. Esta tendência de maior uso da igualdade pelas meninas e da eqüidade pelos meninos foi apontada em estudos anteriores por Benton (1971) e Leventhal e Anderson (1970). Nas demais situações e na análise da quantidade de balas distribuídas, não houve diferenças significativas entre os sexos, concordando com os estudos de Lane e Coon (1972) e Lerner (1974).

Os dados indicaram que, em geral, não há diferença significativa entre as situações de finalização das histórias. No entanto, entre cinco e seis anos, há uma maior concordância da criança com as distribuições apresentadas, demonstrando o quanto elas são mais sugestionáveis nesta faixa etária. Este resultado é coerente com a proposição de Piaget (1932/1977) de que a criança até sete ou oito anos não apresenta uma noção própria de justiça distributiva, uma vez que a mesma implica uma certa autonomia e libertação em relação à autoridade adulta. Já nas demais faixas etárias, os sujeitos mantiveram o princípio que acreditavam ser o mais correto, não se deixando influenciar em suas respostas, confirmando os resultados de Sales (2000), que demonstrou um desenvolvimento progressivo da autonomia na passagem gradativa do princípio de igualdade para o princípio de eqüidade.

As justificativas das respostas permitiram a identificação de sub-estágios, bem caracterizados, possibilitando assim descrever de forma mais precisa em que nível de raciocínio se encontrava a resposta apresentada pela criança ao fazer a distribuição da recompensa ou ao julgar uma distribuição já realizada. Estes sub-estágios apresentam um padrão evolutivo demonstrado por correlações elevadas com a idade das crianças. Verificou-se que a maioria das crianças que utilizam o princípio da autoridade, nas situações de distribuição igualitária e eqüitativa, se encontra no subestágio $1 \mathrm{~A}$. Nestas situações as crianças apenas concordaram com a distribuição apresentada, sem saber explicar, pois para elas o que é feito pela figura de autoridade é justo por princípio.

Quanto aos sub-estágios do princípio de igualdade, verificou-se diferenças nas freqüências do sub-estágio 2 , entre a situação em que a criança faz a distribuição da recompensa e as situações em que a criança julga uma distribuição. Na situação em que a criança faz a distribuição não é possível identificar o princípio de autoridade, e, desta forma, a freqüência das respostas igualitárias foi maior na faixa de cinco a seis anos, embora geralmente classificadas no sub-estágio 2 , no qual a criança não sabia justificar sua distribuição.

Os sub-estágios 3 e 4 de igualdade predominaram na faixa etária de nove a dez anos, quando então as crianças já apresentavam argumentos que fundamentavam o princípio utilizado. Observou-se que o sub-estágio 5, último identificado para descrever o princípio de igualdade, apresentou maior freqüência na faixa de 13 a 14 anos, em todas situações. Isto demonstra que as crianças desta faixa etária, apesar de ainda estarem utilizando o princípio de igualdade na sua distribuição, provavelmente já estejam em fase de transição para o próximo nível. Os sub-estágios do princípio de eqüidade, apesar de terem sido identificados em todas as faixas etárias, concentraram-se na faixa etária de 13 a 14 anos. O subestágio 7, com apenas uma exceção, foi identificado somente na faixa de 13 a 14 anos, demonstrando que este tipo de raciocínio é o mais desenvolvido em termos de justiça distributiva.

Foi observado que o reconhecimento da injustiça tende a aumentar com a idade. Nesta situação, ocorreu a 
mesma evolução no uso dos princípios que nas demais situações, levando à conclusão de que o princípio utilizado para reparar a injustiça é o mesmo utilizado para determinar a distribuição nas demais situações. No entanto, pode-se também observar que o princípio de eqüidade alcançou uma freqüência superior na situação de distribuição injusta, nas faixas etárias de cinco a seis anos e de nove a dez anos, nos dois tipos de condições estudados. Este resultado poderia indicar que, frente a uma situação de distribuição injusta, as crianças usariam mais o princípio de eqüidade como forma de reparar a injustiça.

A capacidade (ou sua presumível ausência) da criança em usar proporção na distribuição da recompensa não afetou a utilização dos princípios distributivos nas condições empregadas neste estudo. Observou-se que as crianças, nas três faixas etárias, foram capazes de usar distribuições eqüitativas em todas as condições apresentadas. Estes dados contrariam a proposição de Hook (1982) de que a eqüidade proporcional surge somente a partir dos 13 anos, quando a capacidade de usar proporções se desenvolve. Nossos resultados concordam, no entanto, com Leventhal, Popp e Sawyer (1973), Nelson e Dweck (1977) e Anderson e Butzin (1978), que também apontam a possibilidade da criança pré-escolar usar a eqüidade na alocação de recompensa.

Os resultados deste estudo permitem concluir que há evidências suficientes para confirmar a existência de três períodos distintos no desenvolvimento da justiça distributiva, bem como a existência de sub-estágios em cada um destes períodos. Os estágios e os sub-estágios, além de bem caracterizados, são consistentes, podendo ser observados nas diferentes situações e condições estudadas. Dessa forma, pode-se também concluir que, mesmo com variações na metodologia utilizada, usandose situações em que a criança faz a distribuição ou situações em que julga distribuições, ou ainda usando como variável a quantidade ou a qualidade na produção, pode-se chegar ao modelo de desenvolvimento de justiça aqui descrito.

\section{Referências}

Adams, J. S. (1965). Inequity in social exchange. Em L. Berkowitz (Org.), Advances in Experimental Social Psychology (pp. 272-276). New York: Academic Press.

Assmar, E. M. L. (1985). Estudo comparativo das razões para alocação de recursos em situaçẽes de lucro e perda num contexto de justiça distributiva e processual (Relatório Técnico $\mathrm{N}^{\circ}$ 6). Rio de Janeiro: CBPP/ISOP/FGV.

Assmar, E. M. L., Ferraz, A. V. de F., Holanda, F. C. A., Jablonski, B., Mendonça, E. M. R., Moreira, A. M. V. \& Rodrigues, A. (1987). Justiça distributiva no Brasil: Uma perspectiva psicossocial. Arquivos Brasileiros de Psicologia, 39, 3-13.

Benton, A. A. (1971). Productivity, distributive justice and bargaining among children. Journal of Personality and Social Psychology, 18, 68-78.
Cook, K. S. \& Hegtvedt, K. A. (1983). Distributive justice, equity and equality. Annual Review of Sociology, 9, 217-241.

Damon, W. (1975). Early conceptions of positive justice as related to the development of logical operations. Child Development, 46, 301-312.

Deutsch, M. (1975). Equity, equality and need: What determines which value will be used as the basis of distributive justice? Journal of Social Issues, 3l, 137-149.

Deutsch, M. (1986). Cooperation, conflict and justice. Em H. W. Bierhoff, R. L. Cohen \& J. Greenberg (Orgs.), Justice in social relations (pp. 317).New York: Plenum Press.

Enright, R. D., Franklin, C. C. \& Manheim, L. A. (1980). Children's distributive justice reasoning: A standardized and objective scale. Developmental Psychology, 16, 193-202.

Enright, R. D., Enright, W. F., Manheim, L. A. \& Harris, B. E. (1980). Distributive justice development and social class. Developmental Psychology, 16, 555-563.

Furby, L. (1986). Psychology and justice. Em R. L. Cohen (Org.), Views from the social sciences (pp. 153-203). New York: Plenum Press.

Hook, J. G. \& Cook, T. D. (1979). Equity theory and the cognitive ability of children. Psychological Bulletin, 86, 429-444.

Hook, J. G. (1982). Development of equity and altruism in judgments of reward and damage allocation._Developmental Psychology, 18, 825-834.

Hook, J. G. (1983). The development of children's equity judgments. Em R. L. Leahy (Org.), The child's construction of social inequality (pp.207-222). New York: Academic Press.

Hutz, C. S., Vargas, S. \& Conti, L. (1989). Justiça distributiva em estudantes universitários: Efeito da temporalidade do lucro [Resumo]. Em Sociedade Brasileira de Psicologia (Org.), Resumos de comunicações científicas, XIX Reunião Anual de Psicologia (p. 162). Ribeirão Preto: SBP.

Hutz, C. S., Vargas, S. \& Conti, L. (1991, julho). Task effects on the preference for equality and equity rules among Brazilian students. Trabalho apresentado no XXIII Interamerican Congress of Psychology, S. Jose, Costa Rica.

Hutz, C. S., Vargas, S. \& Conti, L. (1994). Rules used by Brazilian students in systematic and nonsystematic reward allocation. Journal of Social Psychology, 134, 331-338.

Kohlberg, L. (1984). Essays on moral development: The psychology of moral development. Boston: Univ. of Harvard Press.

Lane, I. M. \& Coon, R. C. (1972). Reward allocation in preschool children. Child Development, 43, 1382-1389.

Lerner, M. J. (1974). The justice motive: "Equity" and "parity" among children. Journal of Personality and Social Psychology, 29, 539-550.

Leventhal, G. S. \& Anderson, D. (1970). Self-interest and the maintenance of equity. Journal of Personality and Social Psychology, 15, 57-62.

Peterson, C., Peterson, J. \& McDonald, N. (1975). Factors affecting reward allocation by preschool children. Child Development, 46, 942-947.

Piaget, J. (1977). O julgamento moral na criança. (E. Lenardon, Trad.) São Paulo: Mestre Jou. (Trabalho original publicado em 1932).

Rodrigues, A. (1985). A percep̧ãa da justiça na distribuição de lucros e perdas: Um estudo psicossocial. (Relatório Técnico $\mathrm{N}^{\circ}$ 5). Rio de Janeiro: CBPP/ ISOP/FGV.

Rodrigues, A. \& Assmar, E. M. L. (1988). On some aspects of distributive justice in Brazil. Revista Interamericana de Psicologia, 22, 1-20.

Sales, E. M. B. (2000). O conceito de justiça distributiva relacionado às normas sociais escolares. Psicologia: Reflexão e Crítica, 13, 49-58.

Sampson, E. E. (1975). On justice as equality. Journal of Social Issues, 31, 4564.

Vikan, A. (1986). Justice concept development as shown in reward allocations. Scandinavian Journal of Psychology, 27, 346-353.

Wender, I. (1986). Children's use of justice principles in allocation situation. Em H. W. Bierhoff, R. L. Cohen \& J.Greenberg (Orgs.), Justice in social relations (249-264). New York: Plenum Press. 
Sobre os autores:

Débora Dalbosco Dell'Aglio é psicóloga, com Doutorado em Psicologia do Desenvolvimento pela UFRGS, e professora do Curso de Psicologia da UNISINOS-RS.

Cláudio Simon Hutz é psicólogo, Professor Titular do Instituto de Psicologia da UFRGS.

Anexo A

Desenhos Utilizados nas Situações Experimentais
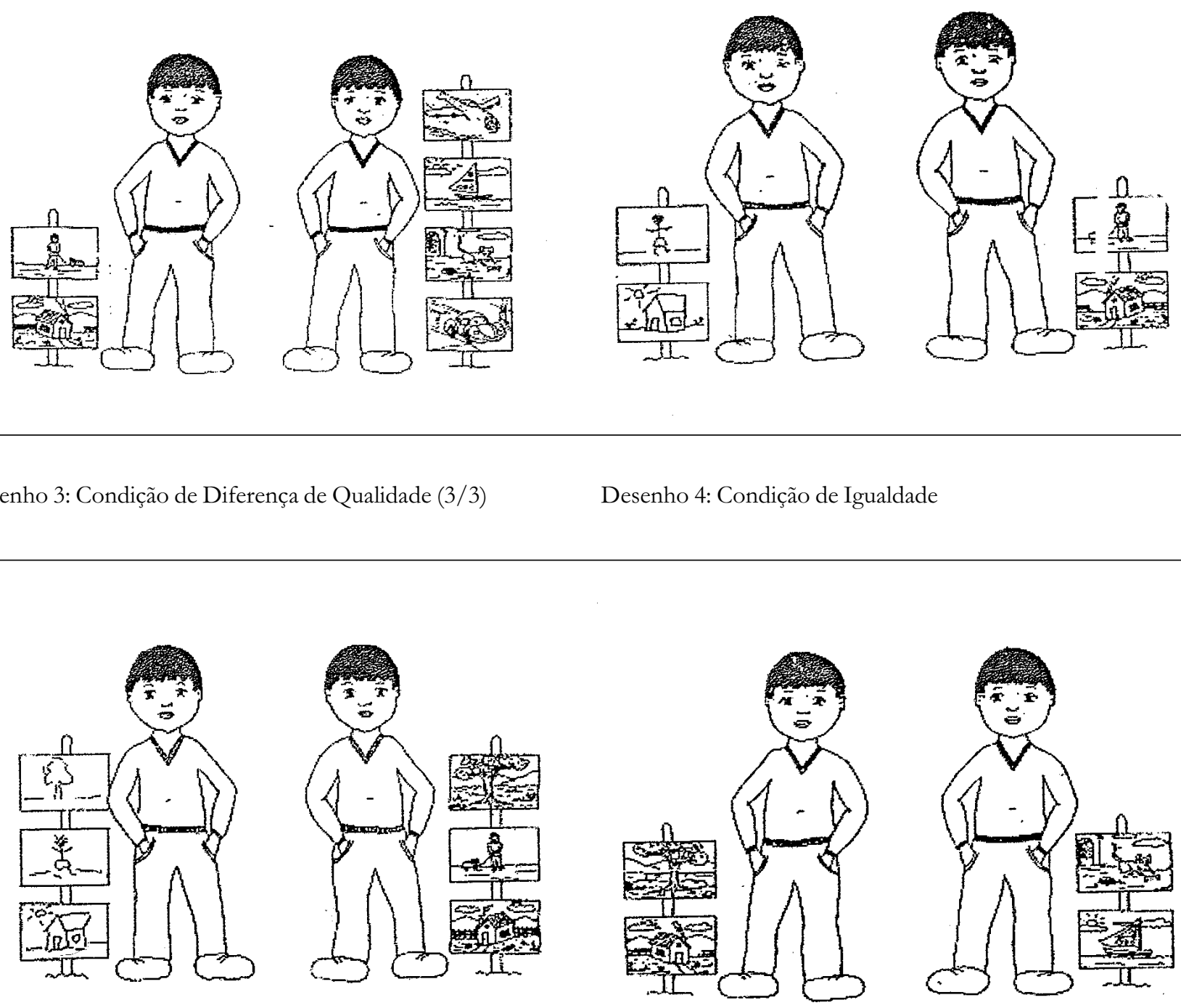